\title{
Study of competitive binding of amlodipine besylate and benazepril hydrochloride to bovine serum albumin and their displacement interaction at the binding site
}

\author{
Israt Jahan ${ }^{1}$, Anna Akter ${ }^{1}$, Irin Dewan ${ }^{1}$, Md. Selim Reza ${ }^{2}$, S. M. Ashraful Islam ${ }^{1 *}$ \\ ${ }^{1}$ Department of Pharmacy, University of Asia Pacific, 74/A Green Road, Dhaka-1215, Bangladesh. \\ ${ }^{2}$ Department of Pharmaceutical Technology, Faculty of Pharmacy, University of Dhaka, Dhaka-1000, Bangladesh.
}

\begin{tabular}{l} 
ARTICLE INFO \\
\hline Article history: \\
Received on: 28/02/2017 \\
Accepted on: 23/04/2017 \\
Available online: 30/06/2017 \\
\hline Key words: \\
Amlodipine Besylate; \\
Benazepril Hydrochloride; \\
Diazepam; Warfarin Sodium; \\
Serum Albumin; Equilibrium \\
Dialysis; Binding Chemistry.
\end{tabular}

\begin{abstract}
The present experiment shows how clinically two important drugs, amlodipine besylate $(\mathrm{AB})$ and benazepril hydrochloride $(\mathrm{BH})$, bind with serum protein and their mutual effect to displace each other from their binding sites. Binding chemistry of amlodipine besylate and benazepril hydrochloride to bovine serum albumin (BSA) was evaluated by equilibrium dialysis method at $\mathrm{pH} 7.4$ and $37^{\circ} \mathrm{C}$ temperature. The binding of these two drugs have been characterized by two sets of association constant: high affinity constant $\left(\mathrm{K}_{1}\right)$ and low affinity association (K2) constant. The non-linear curve of the scatchard plot suggested high affinity binding sites $\left(\mathrm{K}_{1}=\right.$ $\left.8.47 \times 10^{5} \mathrm{M}^{-1}, \mathrm{n}_{1}=1.9\right)$ and low affinity binding sites $\left(\mathrm{K}_{2}=0.33 \times 10^{5} \mathrm{M}^{-1}, \mathrm{n}_{2}=11.7\right)$ for amlodipine besylate. On the other hand for benazepril hydrochloride high affinity constant $\left(\mathrm{K}_{1}\right)$ was $14 \times 10^{5} \mathrm{M}^{-1}\left(\mathrm{n}_{1}=1\right)$ and low affinity constant $\left(\mathrm{K}_{2}\right)$ was $0.31 \times 10^{5} \mathrm{M}^{-1}\left(\mathrm{n}_{2}=16\right)$. Site specific probe displacement data showed that amlodipine besylate primarily binds to site - I (the warfarin sodium site), while the low affinity site of this drug is Site- II (diazepam site) on BSA. On the other hand, benazepril hydrochloride primarily binds to site - II (diazepam site) on BSA. The investigated drugs compete for different site (site-I amlodipine besylate and site-II - benazepril hydrochloride) and they do not displace each other from bovine serum albumin, hence concurrent administration of these two drugs will not alter the therapeutic efficacy of each other and co-administered of these two drugs can be effective as a combination therapy in the management of hypertension.
\end{abstract}

\section{INTRODUCTION}

Nowadays, the most effective way to manage cardiovascular problems is combination therapy. Serum albumin, the most abundant protein in blood plasma, serves as a depot and transport protein for numerous endogenous and exogenous compounds (Kragh-Hansen, 1981). The most outstanding property of albumin is its ability to bind reversibly with different

\footnotetext{
* Corresponding Author

SM Ashraful Islam, Professor, Department of Pharmacy, University of Asia Pacific, 74/A Green Road, Dhaka-1215, Bangladesh. Email: ashraf@uap-bd.edu
}

ligands including fatty acids, amino acids (tryptophan and cysteine), steroids, metals such as calcium, copper, zinc and numerous pharmaceuticals (He and Carter, 1992). From different studies, it is known that there are mainly three high affinity drug binding sites on human serum albumin which are generally termed as warfarin, benzodiazepine and digoxin binding sites which are also denoted as site I, site II, site III, respectively (Fehske et al.,1979; Sudlow et al.,1975, Sudlow et al., 1976; Uddin et al., 2004). When two or more drugs are administered in any biological system they compete for each other to bind with these binding sites. Problems are created when the concomitantly administered drugs show their affinity to the same binding site (Rahman and Sharker, 2009). 
In that case, patient may experience mild to severe alteration in action of drugs than that of individual when administered in different time.

Efficacy as well as toxic profile of drug depends largely on its ability to bind with serum protein. The more binding of drug with plasma protein indicates the less free drug in the blood. It is generally assumed that free drug concentration in the blood is responsible for its action on biological system. In most of the cases only a little percentage of drug remains in free form in plasma. So small displacement of drug from plasma protein may result many fold increment in its activity in the biological system (Alam et al., 2008). The present study has centered mainly on the binding chemistry of amlodipine besylate (calcium channel blocker) and benazepril hydrochloride (angiotensin converting enzyme inhibitor) to BSA. Amlodipine besylate and benazepril hydrochloride are widely used drug for treating hypertension and chest pain (angina). To observe binding chemistry of amlodipine besylate and benazepril hydrochloride on BSA, the association constants as well as the binding sites to Bovine Serum Albumin (BSA) were calculated by scatchard analysis (Scatchard, 1949) at $\mathrm{pH} 7.4$ and $37^{\circ} \mathrm{C}$. In this study BSA was used in lieu of HAS (human serum albumin), because of its structural similarity with HSA, low cost and easy availability.

To find out binding sites of amlodipine and benazepril to plasma protein, displacement effect from serum protein upon concurrent administration and suitability for concurrent administration were the main purpose of this study.

\section{MATERIALS AND METHODS}

\section{Drugs and Reagents}

Experimental drugs amlodipine besylate and benazepril hydrochloride were kind gift from Incepta Pharmaceuticals Ltd, Bangladesh. Probe warfarin sodium and diazepam were collected from Aristo Pharma Ltd, Bangladesh. Methanol and Ethanol used in this experiment were of analytical grade and purchased from Merck K GaA, Germany. Disodium hydrogen phosphate anhydrous $\left(\mathrm{Na}_{2} \mathrm{HPO}_{4}\right)$ and potassium dihydrogen phosphate $\left(\mathrm{KH}_{2} \mathrm{PO}_{4}\right)$ were purchased from Merck Specialties Pvt. Ltd, India. Ortho-Phosphoric Acid and Acetonitrile (used as mobile phase) were purchased from E. Merck, Darmstadt, Germany. Cellulose membrane dialysis tube (Molecular cut off at 3500 Daltons) was purchased from Medicell Membrane Ltd, 239 Liverpool Road, London. Bovine serum albumin (fatty acid free, fraction V and 9698\%) was purchased from the Lobe Chemie Pvt. Ltd, India. Molecular weight of the protein is approximately 66,210 Dalton with 581 amino acids and 4.7 isoelectric points.

\section{Instruments}

UV-VIS Spectrophotometer (UV-1700, Shimadzu, Japan), HPLC system consisting a CMB-20 alit system Controller, two LC-20AT pumps, SIL-20A auto sampler and CTO-10ASVP column oven (Shimadzu, Japan) and Sonicator (PowerSonic505) were used in the study.

\section{Preparation of membrane}

Recommended tubing length $(9 \mathrm{~cm})$ was calculated based on the desired sample volume and the tubing flat wide. The supplied membrane was cut into small pieces ( $9 \mathrm{~cm}$ in length) and taken in $500 \mathrm{~mL}$ beaker containing de-ionized water. The pieces of membranes were immersed beneath the de-ionized water and heated between $65-70^{\circ} \mathrm{C}$ for $10-12$ hours in order to remove sulfur. Hot water was replaced by fresh de-ionized water at every one hour interval for efficient removal of sulfur. The prepared pieces of membrane were kept in a breaker containing fresh deionized water and preserved in a refrigerator (chilling chamber) until use.

\section{Preparation of protein (BSA) solution at pH7.4}

To prepare $100 \mathrm{ml}$ of $2 \times 10^{-5} \mathrm{M}$ solution of BSA 0.133 gm of protein was accurately measured and dissolved in a $100 \mathrm{~mL}$ volumetric flask with the previously prepared phosphate buffer solution of $\mathrm{pH}$ 7.4. This was done carefully and gently so that it did not produce foam. The protein solution was kept in a refrigerator Until use.

\section{Preparation of standard curve}

Stock solution (1 $\left.\mathrm{x} 10^{-3} \mathrm{M}\right)$ of amlodipine besylate, benazepril hydrochloride, warfarin sodium and diazepam were prepared as by dissolving calculated amount of drugs in $100 \mathrm{ml}$ buffer solution of $\mathrm{pH} 7.4$ separately. Then these solutions were diluted separately with buffer solution of $\mathrm{pH} 7.4$ in $10 \mathrm{ml}$ volumetric flask to have the following concentration: $0.5 \times 10^{-5} \mathrm{M}$, $0.8 \times 10^{-5} \mathrm{M}, 1 \times 10^{-5} \mathrm{M}, 2 \times 10^{-5} \mathrm{M}, 3 \times 10^{-5} \mathrm{M}, 4 \times 10^{-5} \mathrm{M}$, and $5 \times 10^{-5} \mathrm{M}$. After proper mixing absorbance were determined at $241 \mathrm{~nm}$ (amlodipine besylate), $239 \mathrm{~nm}$ (benazepril hydrochloride), $315 \mathrm{~nm}$ (warfarin sodium) and $258.5 \mathrm{~nm}$ (diazepam) by a UV spectrophotometer (UV-1700). The standard curve was obtained by plotting the absorbance values against the corresponding concentrations.

\section{Determination of association constant}

Association constant and corresponding binding site (n) of amlodipine besylate and benazepril hydrochloride were determined by scatchard plot method (Scatchard, 1949) utilizing the equilibrium dialysis technique. In this method a curve was obtained by plotting r/Df versus $r$ values where Df stands for the molar concentration of free drug and $r$ is the ratio of the molar concentration of bound drug $\left[\mathrm{D}_{\mathrm{B}}\right]$ to the molar concentration of protein $\left[\mathrm{P}_{\mathrm{t}}\right]$.

$$
\mathrm{r}=\frac{\left[D_{B}\right]}{\left[P_{t}\right]}
$$

The extrapolation of the plot gives an intercept on $\mathrm{Y}$-axis and $\mathrm{X}$-axis represents $\mathrm{nKa}$ values. Here, $\mathrm{Ka}$ and $\mathrm{n}$ stand for association constant and corresponding number of binding site on the protein molecule, respectively. The scatchard plot in the study represents both high affinity and low affinity sites for each drug on the BSA molecule. 
Determination of association constant of amlodipine besylate bound to BSA at pH 7.4 and $37^{\circ} \mathrm{C}$

Five $\mathrm{mL}$ of $2 \times 10^{-5} \mathrm{M}$ BSA solution were taken in each of the seven test tubes and amlodipine besylate was added in six test tube and the mixture was diluted by buffer solution ( $\mathrm{pH} \mathrm{7.4,} \mathrm{up} \mathrm{to}$ $10 \mathrm{ml}$ ) to make the drug concentration $2 \times 10^{-5} \mathrm{M}, 4 \times 10^{-5} \mathrm{M}, 8 \times 10^{-}$ ${ }^{5} \mathrm{M}, 12 \times 10^{-5} \mathrm{M}, 16 \times 10^{-5} \mathrm{M}, 18 \times 10^{-5} \mathrm{M}$. The seventh test tube containing $5 \mathrm{ml}$ BSA and $5 \mathrm{ml}$ buffer solution was marked as "control". The solutions were then properly mixed and allowed to stand for 30 minutes in order to ensure maximum binding of amlodipine besylate to BSA. From each of the test tube, $3.5 \mathrm{~mL}$ solution was pipetted out and poured into seven previously prepared semi permeable membrane tubes. Two ends of the membrane tubes were folded and fixed with thread so that there was no leakage. The membrane tubes were then immersed in seven separate $50 \mathrm{~mL}$ conical flasks containing $20 \mathrm{~mL}$ of phosphate buffer solution of $\mathrm{pH}$ 7.4. The mouths of the conical flasks were covered by aluminum foil. These conical flasks were then placed in a water bath shaker for dialysis for 12 hours at $37^{\circ} \mathrm{C}$ and $20 \mathrm{rpm}$. After completion of dialysis samples were collected from each flask. Free concentrations of amlodipine besylate were measured by UV-spectrophotometer at a wavelength of $241 \mathrm{~nm}$.

\section{Determination of association constant of benazepril hydrochloride bound to BSA at pH 7.4 and $37{ }^{\circ} \mathrm{C}$}

Association constant of benazepril hydrochloride was calculated by using the same method as mentioned above. Five $\mathrm{mL}$ of $2 \times 10^{-5} \mathrm{M}$ solution were taken in each of the seven test tubes and benazepril hydrochloride was added and diluted by buffer solution (up to $10 \mathrm{ml}$ ) to make the concentration $2 \times 10^{-5} \mathrm{M}, 4 \times 10^{-5} \mathrm{M}, 8 \times 10^{-}$ ${ }^{5} \mathrm{M}, 12 \times 10^{-5} \mathrm{M}, 16 \times 10^{-5} \mathrm{M}, 18 \times 10^{-5} \mathrm{M}$. The above method was followed for dialysis upto 12 hours and finally free concentrations of Benazepril $\mathrm{HCl}$ were measured by $\mathrm{UV}$-spectrophotometer at a wavelength of $239 \mathrm{~nm}$.

\section{Identification and characterization of binding site of drugs on BSA at pH 7.4 and $37^{\circ} \mathrm{C}$}

The specificity and relative strength of binding of a drug to albumin is generally determined by its ability to displace the probes specific for particular sites on albumin. In this study, we examined different site specific probes to advance our understanding of the drug-BSA interaction and characterization of binding sites of the drugs used in the study.

Binding sites of amlodipine besylate and benazepril hydrochloride on BSA were identified by using two site specific probes: warfarin sodium (site-I specific probe) and diazepam (siteII specific probe). In the presence of the mixture of the probe and BSA at a constant ratio $\left(1: 1,1 \times 10^{-5} \mathrm{M}: 1 \times 10^{-5} \mathrm{M}\right)$, different concentrations of drugs were added separately. Free concentrations of the probe and drug were then determined by the equilibrium dialysis method to see whether there was any change in the free concentrations of the probe by the addition of the drug. Samples were analyzed by a validated HPLC method. The mobile phase of the HPLC method was a mixture of acetonitrile-buffer $(\mathrm{pH} 2.5)$
$(60: 40 \mathrm{v} / \mathrm{v})$ which was pumped at a flow rate of $1 \mathrm{ml} / \mathrm{min}$ through the column $\left(\mathrm{C}_{18} ; 5 \mu, 4.6 \times 150 \mathrm{~mm}\right.$, Waters, USA) at ambient temperature. Buffer solution was prepared by dissolving $2 \mathrm{gm}$ of potassium hydrogen phosphate in HPLC grade water to make a final volume $500 \mathrm{ml}$. pH was adjusted with ortho-phosphoric acid ( $\mathrm{pH}$ 2.5). The injection volume was $10 \mu \mathrm{l}$. The mobile phase was filtered through $0.2 \mu$ membrane filter and degassed prior to use suction pump with negative pressure filtration. Concentrations were measured at $248 \mathrm{~nm}$ by UV detector at a sensitivity of 0.00001 . The run time was at 15 minutes and column temperature was maintained at $25^{\circ} \mathrm{C}$. Prior to injection of sample, the column was equilibrated for 30 minutes with mobile phase.

\section{Determination of binding site of amlodipine besylate using warfarin sodium as a site-I specific probe}

Five $\mathrm{mL}$ of $2 \times 10^{-5} \mathrm{M}$ BSA solution, previously prepared in phosphate buffer of $\mathrm{pH} 7.4$, was taken in each of the six cleaned and dried test tubes. Ten $\mu \mathrm{L}$ of $1 \times 10^{-2} \mathrm{M}$ warfarin (as warfarin sodium) solution was then added to the five out of six test tubes. Thus the final ratio between protein and warfarin was $1: 1\left(1 \times 10^{-5}\right.$ M: $\left.1 \times 10^{-5} \mathrm{M}\right)$ in each of these five test tubes. The sixth test tube containing only BSA solution was marked as "Blank" or "Control". These mixtures were allowed to stand for 10 minutes for allowing binding of the warfarin to its particular binding site. Amlodipine besylate solution $\left(1 \mathrm{x} 10^{-3} \mathrm{M}\right)$ was added with increasing concentrations into four out of five test tubes containing 1:1 mixture of BSA- Warfarin. The final ratios between amlodipine besylate and protein were $1: 1,2: 1,4: 1$ and $6: 1$ and made the final volume by respective buffer solution. Amlodipine besylate was not added in the one test tube containing the BSAWarfarin mixture $(1: 1)$. These mixtures were allowed to stand for 10 minutes for allowing binding of the warfarin to its particular binding site. From each of the test tube, $3.5 \mathrm{~mL}$ solution was taken and poured into six different semi-permeable membrane tubes. Two ends of the membrane tube were folded and fixed with thread to ensure that there was no leakage. The membrane tubes were then immersed in six separate $50 \mathrm{~mL}$ conical flasks containing 20 $\mathrm{mL}$ of phosphate buffer solution of $\mathrm{pH}$ 7.4. The conical flasks were then placed in a water bath shaker for dialysis at $37^{\circ} \mathrm{C}$ and 20 rpm and shaking was continued for about 12 hours. After completion of dialysis, samples were collected from each flask. Then the samples were filtered with syringe filter and the free concentrations of warfarin and amlodipine besylate were measured by validated HPLC technique.

\section{Determination of binding site of amlodipine besylate using diazepam as a site-II specific probe}

Bind site of amlodipine besylate using diazepam as a site-II specific probe was determined by using the same method as mentioned above. Ten $\mu \mathrm{L}$ of $1 \times 10^{-2} \mathrm{M}$ diazepam solution was used in place of warfarin solution. After completion of dialysis, samples were collected from each flask. Then the samples were filtered with syringe filter and the free concentrations of diazepam and amlodipine besylate were measured by HPLC technique. 


\section{Determination of binding site of benazepril hydrochloride using warfarin sodium as a site-I specific probe}

Five $\mathrm{mL}$ of $2 \times 10^{-5} \mathrm{M}$ BSA solution, previously prepared in phosphate buffer of $\mathrm{pH} 7.4$, was taken in each of the six cleaned and dried test tubes. Ten $\mu \mathrm{L}$ of $1 \times 10^{-2} \mathrm{M}$ Warfarin (as Warfarin Sodium) solution was then added to the five out of six test tubes. Thus the final ratio between protein and Warfarin was 1:1 $\left(2 \times 10^{-5} \mathrm{M}: 1 \times 10^{-2} \mathrm{M}\right)$ in each of these five test tubes. The sixth test tube containing only BSA solution was marked as "Blank" or "Control". These mixtures were allowed to stand for 10 minutes for allowing binding of the warfarin to its particular binding site. Solution $\left(1 \times 10^{-3} \mathrm{M}\right)$ was added with increasing concentrations into four out of five test tubes containing 1:1 mixture of BSA- Warfarin. The final ratios between benazepril hydrochloride and protein were 1:1, 2:1, 4:1 and 6:1 and made the final volume by respective buffer solution. Benazepril hydrochloride was not added in the one test tube containing the BSA- Warfarin mixture (1:1). These mixtures were allowed to stand for 10 minutes for allowing binding of the warfarin to its particular binding site. The solutions were then properly mixed and allowed to stand for 10 minutes in order to ensure maximum binding of warfarin and benazepril hydrochloride to BSA. From each of the test tube, $3.5 \mathrm{~mL}$ of solution was taken and poured into six different semi-permeable membrane tubes. Two ends of the membrane tube were folded and fixed with thread to ensure that there was no leakage. The membrane tubes were then immersed in six separate $50 \mathrm{~mL}$ conical flasks containing $20 \mathrm{~mL}$ of phosphate buffer solution of $\mathrm{pH}$ 7.4. The conical flasks were then placed in a water bath shaker for dialysis at $37^{\circ} \mathrm{C}$ and $20 \mathrm{rpm}$ and shaking was continued for about 12 hours. After completion of dialysis, samples were collected from each flask. Then the samples were filtered with syringe filter and the free concentrations of Warfarin and Benazepril Hydrochloride were measured by HPLC technique.

\section{Determination of binding site of benazepril hydrochloride using diazepam as a site-II specific probe}

Binding site of Benazepril Hydrochloride using Diazepam as a site-II specific probe was determined by using the same method as mentioned above. Ten $\mu \mathrm{L}$ of $1 \times 10^{-2} \mathrm{M}$ diazepam solution was used in place of warfarin solution. After completion of dialysis, samples were collected from each flask. Then the samples were filtered with syringe filter and the free concentrations of diazepam and Benazepril Hydrochloride were measured by HPLC technique.

\section{Displacement study of amlodipine besylate from BSA on addition of benazepril hydrochloride}

In the mixture of fixed ratio of amlodipine besylate and BSA $\left(\left(1: 1,2 \times 10^{-5} \mathrm{M}: 2 \times 10^{-5} \mathrm{M}\right)\right.$ different concentrations of benazepril hydrochloride were added. The changes in the free concentration of amlodipine besylate and benazepril hydrochloride were determined by HPLC analytical technique Five $\mathrm{mL}$ of $2 \times 10^{-5}$ M BSA solution previously prepared in phosphate buffer of $\mathrm{pH}$
7.4 was taken in each of the five cleaned and dried test tubes. Ten $\mu \mathrm{L}$ of $1 \times 10^{-2}$ Amlodipine Besylate solution was added to the four out of five test tubes. Thus the final ratio of BSA and Amlodipine Besylate was 1:1 $\left(2 \times 10^{-5} \mathrm{M}: 2 \times 10^{-5} \mathrm{M}\right)$ in each of these four test tubes. The fifth test tube containing only BSA solution was marked as "Blank" or "Control". Benazepril hydrochloride solution was added with increasing concentrations into three out of four test tubes containing 1:1 mixture of BSA- amlodipine besylate. The final ratios between benazepril hydrochloride and BSA were 1:1, 2:1 and 4:1. Benazepril hydrochloride was not added in the one test tube containing BSA- amlodipine besylate mixture (1:1).The solutions were then properly mixed and allowed to stand for 10 minutes to ensure maximum binding to BSA. From each test tube $3.5 \mathrm{~mL}$ solution was taken into five different semi-permeable membrane tubes.

Two end of the membrane tube were folded and fixed with thread to ensure that there was no leakage. The membrane tubes were then immersed in five separates $50 \mathrm{~mL}$ conical flasks containing $20 \mathrm{~mL}$ of phosphate buffer solution of $\mathrm{pH}$ 7.4.The conical flasks were then placed in a waterbath shaker for dialysis at $37{ }^{\circ} \mathrm{C}$ and $20 \mathrm{rpm}$ and shaking was continued for 12 hours. After completion of dialysis, samples were collected from each flask. The samples were filtered through syringe filter and the free concentrations of amlodipine besylate and benazepril hydrochloride were measured by HPLC analytical method.

\section{RESULTS AND DISCUSSION}

Equations for standard curves are presented in table 1. Equations are utilized to calculate the value of free drug concentration.

Table 1: Equations for standard curve of amlodipine besylate, benazepril $\mathrm{HCl}$, warfarin sodium and diazepam.

\begin{tabular}{cccc}
\hline \multicolumn{4}{c}{ Equations for standard curve } \\
\hline $\begin{array}{c}\text { amlodipine } \\
\text { besylate }\end{array}$ & benazepril HCl & warfarin sodium & diazepam \\
\hline $\mathrm{Y}=0.189 \mathrm{x}-$ & $\mathrm{Y}=0.145 \mathrm{x}-$ & $\mathrm{Y}=0.125 \mathrm{x}+$ & $\mathrm{Y}=0.092 \mathrm{x}-$ \\
0.010 & 0.016 & 0.000 & 0.001 \\
\hline
\end{tabular}

\section{Determining association constant and number of binding sites}

Drug-protein binding are mainly of two types -strong affinity binding to a smaller number of sites and weak affinity binding to a large number of sites (kabir et al., 2010). In this present experiment, the binding parameters of amlodipine besylate and benazepril hydrochloride have been characterized by scatchard plot. The non-linear curve of plot confirmed the presence of at least two classes of binding sites of experimental drugs to BSA.

By non-linear curve (scatchard plot analysis) of equilibrium dialysis data from table 2 , showed that at $\mathrm{pH} 7.4$ and $37{ }^{\circ} \mathrm{C}$ association constant and number of bonding site of amlodipine besylate are about $8.47 \times 10^{5} \mathrm{M}^{-1}$ and 1.9 , respectively at high affinity binding site. On the contrary, at low affinity binding site, association constant and number of binding site were found about $0.33 \times 10^{5} \mathrm{M}^{-1}$ and 11.7 respectively (Fig. 1). 
Table 2: Data for determination of association constant of amlodipine besylate bound to BSA at $\mathrm{pH} 7.4$ and $37{ }^{\circ} \mathrm{C}$

\begin{tabular}{|c|c|c|c|c|c|c|}
\hline \# & 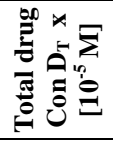 & $\frac{\mathscr{c}}{4}$ & 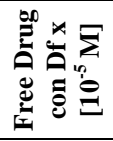 & 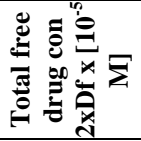 & 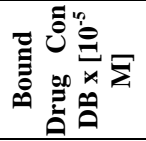 & 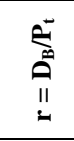 \\
\hline 1 & 2 & 0.005 & 0.079 & 0.159 & 1.841 & 0.921 \\
\hline 2 & 4 & 0.080 & 0.476 & 0.952 & 3.048 & 1.524 \\
\hline 3 & 8 & 0.198 & 1.101 & 2.201 & 5.799 & 2.899 \\
\hline 4 & 12 & 0.337 & 1.836 & 3.672 & 8.328 & 4.164 \\
\hline 5 & 16 & 0.410 & 2.222 & 4.444 & 11.556 & 5.778 \\
\hline 6 & 18 & 0.481 & 2.598 & 5.196 & 12.804 & 6.402 \\
\hline
\end{tabular}

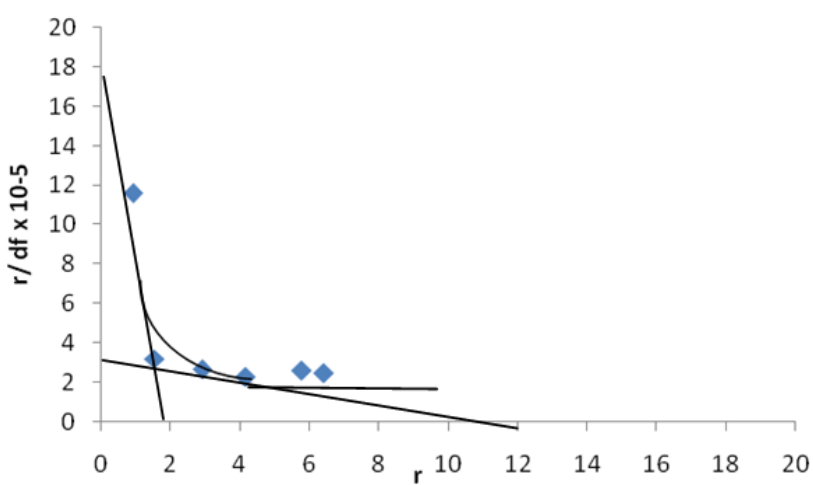

Fig. 1: Scatchard plot for the binding of amlodipine besylate to BSA by equilibrium dialysis at $\mathrm{pH} 7.4$ and $37^{\circ} \mathrm{C}$

Table 3: Data for determination of association constant of benazepril hydrochloride bound to BSA at $\mathrm{pH} 7.4$ and $37{ }^{\circ} \mathrm{C}$.

\begin{tabular}{|c|c|c|c|c|c|c|c|}
\hline 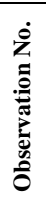 & 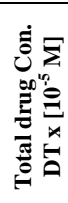 & $\frac{n}{4}$ & 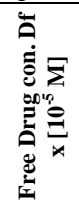 & 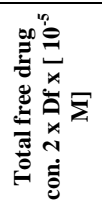 & 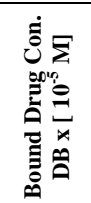 & 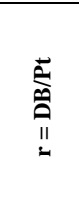 & 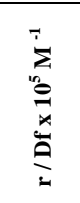 \\
\hline 1 & 2 & 0.010 & 0.179 & 0.359 & 1.641 & 0.821 & 4.577 \\
\hline 2 & 4 & 0.040 & 0.386 & 0.772 & 3.228 & 1.614 & 4.179 \\
\hline 3 & 8 & 0.100 & 0.800 & 1.600 & 6.400 & 3.200 & 4.000 \\
\hline 4 & 12 & 0.159 & 1.207 & 2.414 & 9.586 & 4.793 & 3.971 \\
\hline 5 & 16 & 0.220 & 1.628 & 3.255 & 12.745 & 6.372 & 3.915 \\
\hline 6 & 18 & 0.270 & 1.972 & 3.945 & 14.055 & 7.028 & 3.563 \\
\hline
\end{tabular}

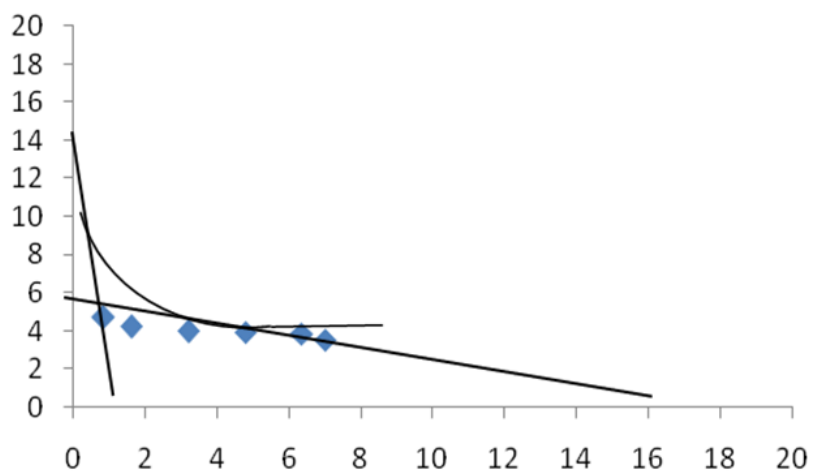

Fig. 2: Scatchard plot for the binding of benazepril hydrochloride to BSA by equilibrium dialysis at $\mathrm{pH} 7.4$ and $37^{\circ} \mathrm{C}$ ( $\mathrm{r}$ in $\mathrm{x}$ axis and $\mathrm{r} / \mathrm{df} \mathrm{x} 10-5$ in y axis).

By non-linear curve (scatchard plot analysis) of equilibrium dialysis data from table 3 showed that at $\mathrm{pH} 7.4$ and $37{ }^{\circ} \mathrm{C}$ association constant and number of binding sites of benazepril hydrochloride are about $14 \times 10^{5} \mathrm{M}^{-1}$ and 1 , respectively at high affinity binding site. On the other hand, at low affinity binding site, association constant and number of binding site were found about $0.31 \times 10^{5}$ and 16 respectively (Fig. 2).

So, the non-linear curves showed the presence of at least two classes of binding sites for the binding of amlodipine besylate and benazepril hydrochloride to BSA.

\section{Determining binding sites of amlodipine besylate and benazepril hydrochloride on BSA}

Binding sites of amlodipine besylate and benazepril hydrochloride were determined by calculating their ability to displace of warfarin sodium and diazepam. The basic principle is that, if a drug is able to displace a probe from its binding site, it is assumed that the drug also binds to that particular site (Alam et al., 2009).

Table 4: Determination of binding site of amlodipine besylate at $\mathrm{pH} 7.4$ and $37{ }^{\circ} \mathrm{C}$ by warfarin sodium as site - I specific probe BSA: Warfarin $(1: 1)(1 \mathrm{x}$ $\left.10^{-5}: 1 \times 10^{-5}\right)$.

\begin{tabular}{|c|c|c|c|c|c|}
\hline 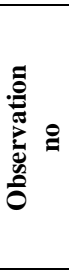 & 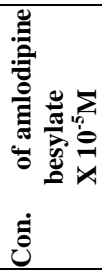 & 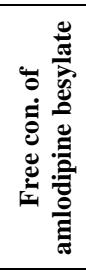 & 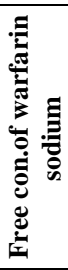 & 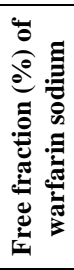 & 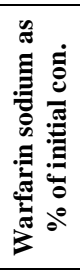 \\
\hline 1 & 0 & 0 & 0.28 & 14 & 100.0 \\
\hline 2 & 1 & 0.0106 & 0.60 & 30 & 214.3 \\
\hline 3 & 2 & 0.189 & 0.80 & 40 & 285.7 \\
\hline 4 & 4 & 0.229 & 1.20 & 60 & 428.6 \\
\hline 5 & 6 & 0.279 & 1.40 & 70 & 500.0 \\
\hline
\end{tabular}

Displacement of warfarin sodium (Table 4) and diazepam (Table 5) by amlodipine besylate are shown graphically in fig. 3. With the increase of concentration of amlodipine from $1 \times 10^{-5} \mathrm{M}$ to $6 \times 10^{-5} \mathrm{M}$, free warfarin sodium was increased from 100 to $500 \%$. On the other hand free concentration of diazepam was increased from 100 to $166.2 \%$.

Table 5: Determination of binding site of amlodipine besylate at $\mathrm{pH} 7.4$ and $37^{\circ} \mathrm{C}$ by diazepam as site - II specific probe BSA: diazepam $(1: 1)$

\begin{tabular}{|c|c|c|c|c|c|}
\hline 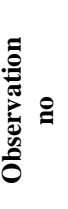 & 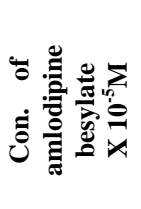 & 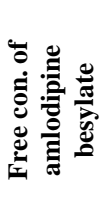 & 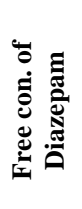 & 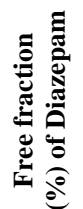 & 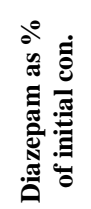 \\
\hline 1 & 0 & 0 & 0.299 & 14.95 & 100 \\
\hline 2 & 1 & 0.198 & 0.336 & 16.8 & 110.38 \\
\hline 3 & 2 & 0.557 & 0.385 & 19.25 & 130.43 \\
\hline 4 & 4 & 0.796 & 0.407 & 20.35 & 136.1 \\
\hline 5 & 6 & 0.956 & 0.497 & 24.85 & 166.2 \\
\hline
\end{tabular}

These findings indicate that addition of amlodipine besylate displaces more warfarin sodium than diazepam. So it can be concluded that amlodipine besylate preferentially binds to SiteI. Similar result was also found previously by other researchers (Alam et al., 2008; Alam et al., 2011). 


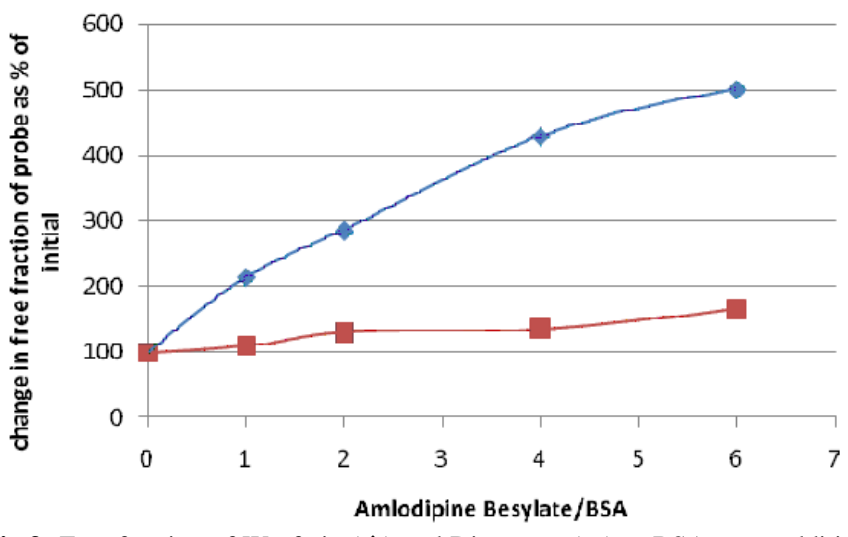

Fig.3: Free fraction of Warfarin ( $\bullet$ ) and Diazepam ( $\mathbf{c})$ to BSA upon addition of amlodipine besylate by equilibrium dialysis at $\mathrm{pH} 7.4$ and $37{ }^{\circ} \mathrm{C}$

Table 6: Determination of binding site of benazepril $\mathrm{HCl}$ at $\mathrm{pH} 7.4$ and $37{ }^{\circ} \mathrm{C}$ by warfarin sodium as site - I specific probe BSA: Warfarin (1:1)

\begin{tabular}{|c|c|c|c|c|c|}
\hline 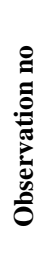 & 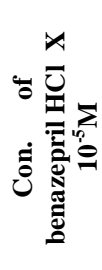 & 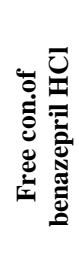 & 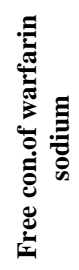 & 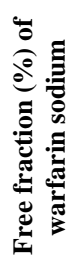 & 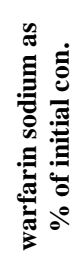 \\
\hline 1 & 0 & 0 & 0.028 & 1.4 & 100 \\
\hline 2 & 1 & 0.172 & 0.028 & 1.4 & 100 \\
\hline 3 & 2 & 0.220 & 0.028 & 1.4 & 100 \\
\hline 4 & 4 & 0.590 & 0.028 & 1.4 & 100 \\
\hline 5 & 6 & 0.911 & 0.028 & 1.4 & 100 \\
\hline
\end{tabular}

Displacement of proves from BSA by benazepril hydrochloride are shown in table 6 and 7. From the tables it is clear that benazepril displaced Diazepam from 100 to $580 \%$ as $\%$ of initial concentration but free concentration of warfarin sodium was found constant $\left(1.4 \times 10^{-5} \mathrm{M}\right)$.

Table 7: Determination of binding site of benazepril $\mathrm{HCl}$ at $\mathrm{pH} 7.4$ and $37{ }^{\circ} \mathrm{C}$ by diazepam as site-II specific probe BSA: Diazepam (1:1).

\begin{tabular}{|c|c|c|c|c|c|}
\hline \# & 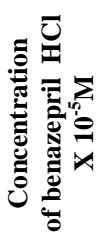 & 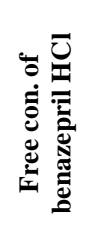 & 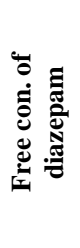 & 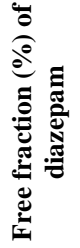 & 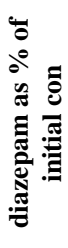 \\
\hline 1 & 0 & 0 & 0.050 & 2.5 & 100 \\
\hline 2 & 1 & 0.0704 & 0.084 & 4.2 & 168 \\
\hline 3 & 2 & 0.242 & 0.170 & 8.5 & 340 \\
\hline 4 & 4 & 0.470 & 0.210 & 10.5 & 420 \\
\hline 5 & 6 & 0.660 & 0.290 & 14.5 & 580 \\
\hline
\end{tabular}

Fig. 4 indicates that addition of benazepril $\mathrm{HCl}$ displaces diazepam than warfarin sodium. So it can be concluded that Benazepril $\mathrm{HCl}$ preferentially binds to Site-II.

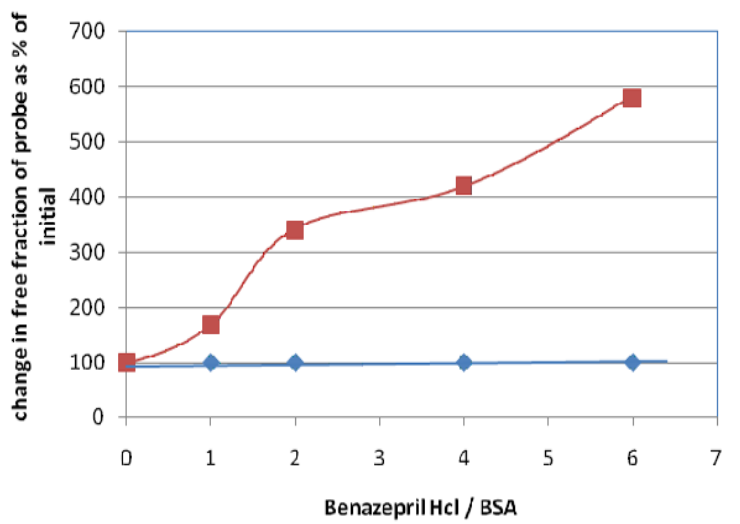

Fig. 4: Free fraction of warfarin $(\diamond)$ and diazepam ( $)$ upon addition of benazepril $\mathrm{HCl}$ to $\mathrm{BSA}$ : prove (1:1) for equilibrium dialysis at $\mathrm{pH} 7.4 \& 37^{\circ} \mathrm{C}$.

\section{Mutual effect of amlodipine besylate and benazepril hydrochloride on binding to BSA (Drug-Drug Interaction)}

In the mixture of fixed ratio of Amlodipine Besylate and BSA $\left(\left(1: 1,2 \times 10^{-5} \mathrm{M}: 2 \times 10^{-5} \mathrm{M}\right)\right.$ different concentrations of Benazepril Hydrochloride were added. The changes in the free concentration of Amlodipine Besylate and Benazepril Hydrochloride were observed.

Table 8: Data for the effect of $\mathrm{BH}$ on $\mathrm{AB}$ on binding to BSA.

\begin{tabular}{|c|c|c|c|c|c|}
\hline \# & 泀 & 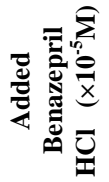 & 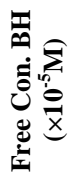 & 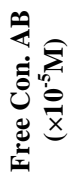 & 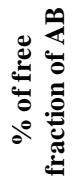 \\
\hline 1 & $1: 1$ & 0 & 0.000 & 0.084 & 8.40 \\
\hline 2 & $1: 1$ & 2 & 0.185 & 0.088 & 8.80 \\
\hline 3 & $1: 1$ & 4 & 0.348 & 0.094 & 9.40 \\
\hline 4 & $1: 1$ & 8 & 0.824 & 0.078 & 7.80 \\
\hline
\end{tabular}

Free fraction of amlodipine besylate remained almost same ( 7.8 to $9.4 \%$ ) with the addition of Benazepril $\mathrm{HCl}$ from $2 \mathrm{x}$ $10^{-5} \mathrm{M}$ to $8 \times 10^{-5} \mathrm{M}$. This indicates that benazepril hydrochloride did not displace amlodipine besylate from bovine serum albumin. Similarly no displacement was found with the addition of amlodipine besylate from $2 \times 10^{-5} \mathrm{M}$ to $8 \times 10^{-5} \mathrm{M}$ in the mixture of benazepril hydrochloride and BSA (1:1). So concurrent administration of these two drugs will not alter the therapeutic efficacy of each other.

\section{CONCLUSION}

It can be assumed that the experimental drugs amlodipine besylate and benazepril hydrochloride preferentially bind with Site-I and Site-II respectively. In addition to Site-I, amlodipine besylate also binds with site-II on the BSA molecule but to a lower extent. As, the investigated drugs compete for different site (Site-I amlodipine besylate and site-II benazepril hydrochloride), concurrent administration of these two drugs will not alter the therapeutic efficacy of each other. Hence the combination dosage 
form of these two drugs will be of therapeutic value as a single dosage form in hypertension.

\section{ACKNOWLEDGEMENT}

We gratefully acknowledge the contribution of Department of Pharmacy, University of Asia Pacific, Bangladesh to give continuous support and valuable guidance, constructive suggestion and benevolent assistance to continue this research work.

\section{Financial support and sponsorship: Nil.}

Conflict of Interests: There are no conflicts of interest.

\section{REFERENCES}

Alam, K.D., Hosain, M.K., Kabir, S., Chowdhury, R.M.A.A., Mehjabeen, S., Mondal, M.S., Abuzar, S.M., Rahman, M.F., In vitro binding chemistry of Amlodipine Besylate (Calcium Channel Blocker) and Atorvastatin Calcium (HMG-CoA Reductase Inhibitor) to serum albumin and their mutual effect to displace each other from the binding site. Am. J. Drug Discov. Dev., 2011; 1(4): 220-230.

Alam, M.A., Awal M.A., Subhan, N., Mostofa, M., In-vitro relationship between protein-binding and free drug concentration of a water-soluble selective beta-adrenoceptor antagonist (atenolol) and its interaction with arsenic. J. Health Popul Nutr, 2009;27: 20-30.

358:208-215.

Alam, M.A., M.A., Awal, N., Subhan, M.H., Sikder, S.M.M., Alam, M., Mostofa M., Uddin S.J., Studies of in-vitro Amlodipine and arsenic displacement interaction at binding sites of bovine serum albumin. Iran. J. pharmacol therapeutics, 2008; 7: 1-8.

Fehske, K.J., Muller, W.E., Wollert, U., A highly reactive tyrosine residue as part of the indole and benzodiazepine binding site of human serum albumin. Biochem. Biophys. Acta, 1979; 577: 346-359.
He, X.M., Carter, D.C., Atomic structure and chemistry of human serum albumin. Nature, 1992;

Kabir, A.F, Uddin, K.N., Sadat, A.F.M.N., Hossain, M., Mazid, A., Interaction of palmitic acid with losartan potassium at the binding sites of bovine serum albumin. Ars. Pharm., 2010; 51: 28-36.

Kragh-Hansen, U., Effects of aliphatic fatty acids on the binding of phenol red to human serum albumin. Biachemical j., 1981; 195: 603613.

Rahman, A.A ., Sarker, S.M., Determination of the binding sites of propanolol HCL on bovine serum albumin by direct and reverse produces. Saudi. Pharma. J., 2009;17: 249-253.

Scatchard G, The attraction of proteins for small molecules and ions. Annals of the New York Academy of Sci., 1949; 51: 660-672.

Sudlow, G., Birkett, D.J., Wade, D.N., Further characterization of two specific binding sites on human serum albumin.Mol, Pharmacol., $1976 ; 12: 1061$.

Sudlow, G., Birkett, D.J., Wade, D.N., The characterization of two binding sites on human serum albumin. Mol. Pharmacol., 1975; 11: 824-832.

Uddin, S.J., Shilpi, J.A., Murshid, G.M.M., Rahman, A.A., Sarder, M.M., Alam, M.A., Determination of the binding sites of arsenic on bovine serum albumin using Warfarin (Site-I Specific Probe) and diazepam (Site-II Specific Probe). J. Biol. Sci., 2004; 4: 609-612.

\section{How to cite this article:}

Jahan I, Akter A, Dewan I, Reza MS, Islam SMA. Study of competitive binding of amlodipine besylate and benazepril hydrochloride to bovine serum albumin and their displacement interaction at the binding site. J App Pharm Sci, 2017; 7 (06): 157163. 